\title{
Andamiajes tridimensionales tipo esponjas basados en bioconjugados colágeno-quitosano como potencial biomaterial para aplicaciones en ingeniería de tejidos
}

\section{Three-dimensional scaffolds Sponges type based in bioconjugates collagen-chitosan as a potential biomaterial for tissue engineering applications}

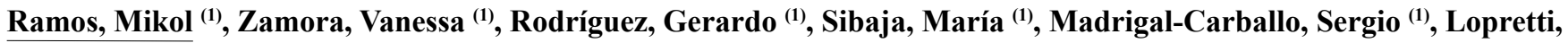 \\ $\operatorname{Mary}^{(2)}$ \\ (1) Escuela de Química, Universidad Nacional, 86-3000 Heredia, Costa Rica - (2) Facultad de Ciencias, UdelaR, Uruguay - \\ (3) Departamento de Proyectos de Bioprocesos, Laboratorio Tecnológico del Uruguay, LATU, Uruguay \\ Contacto: sergio-poliuna@gmail.com \\ Recibido: 15/6/2012 - Aprobado: 14/12/2012
}

\begin{abstract}
Resumen
Nuestro trabajo utiliza quitosano aislado de líneas de desecho de la producción de camarón nativas y colágeno aislado de desechos de la piel de tilapia de cultivo; con estos biopolímeros se sintetizaron materiales compuestos a partir de la mezcla de quitosano y colágeno $(80: 20 \mathrm{v} / \mathrm{v})$. Los compositos de colágeno-quitosano fueron formulados como andamiajes en 3D similares a una esponja, aplicando tecnologías previamente desarrolladas en nuestro grupo de investigación basadas en evaporación de solvente mediante liofilización. Los andamiajes de colágeno-quitosano fueron caracterizados de acuerdo con sus propiedades térmicas (análisis termogravimétrico) y morfología (microscopía de barrido electrónico). Finalmente, se estudió el efecto de la adición de un agente porógeno en las propiedades de absorción de agua y la morfología de los andamiajes tridimensionales. Palabras clave: Quitosano, colágeno, andamiajes 3D, ingeniería de tejidos.
\end{abstract}

\begin{abstract}
We isolated chitosan from native shrimp waste streams and collagen from tilapia skin waste; composite materials were successfully obtained by mixing chitosan with collagen $(80: 20 \mathrm{v} / \mathrm{v})$. Chitosan-collagen composites were formulated as a 3D sponge-like scaffold, applying previously developed methodologies involving solvent casting and freeze drying. Chitosan-collagen 3D scaffolds were characterized according to its thermal behavior (TG) and morphology (SEM). Finally, we study the effect of the addition of a porogenic agent on the water absorption capacity and morphology of the 3D scaffolds. Keywords: Chitosan, colagen, scaffolds 3D, engineering tissue.
\end{abstract}

\section{Introducción}

El colágeno es la matriz extracelular (MEC) más abundante en la naturaleza. Tejidos como dermis y andamiajes fabricados a partir de colágeno han presentado un baja antigenicidad, biodegradabilidad y una biocompatibilidad (propiedades hemostáticas y ligando de células) muy superior en comparación con sistemas fabricados a partir de polímeros sintéticos, como el poliácido láctico (PAL), poliácido glicólico (PAG) y el polietilentereftalato (PET) (Lee et al., 2001; Chen et al., 2005; Pachence, 1996). En su función como andamiaje, los materiales basados en colágeno, en su forma de esponja, han sido considerados los andamiajes tridimensionales con mejores propiedades para la regeneración dérmica (Berthod et al., 1994; Berthod et al., 1993; Park et al., 2003; Ojeh et al., 2001).

Recientemente se ha prestado mucha atención a la utilización del quitosano en aplicaciones biomédicas, por ejemplo, en la cicatrización de heridas, como material para recubrimiento de heridas o quemaduras, agente mucoadhesivo y hemostático, membrana para hemodiálisis y sistema para transporte de sustancias activas (Vasudev et al., 1997; Chandy y Sharma, 1990 y 1993; Hirano, 1996; Muzarelli, 1993; Patel y Amiji, 1996). El quitosano ha sido utilizado para promover la formación de MEC en terapias regenerativas de tejidos (Yaylaoglu et al., 1990; Hollinger y Battison, 1986; Cima et al., 1991; Laurencin et al., 1996; Muzzarelli et al., 1993; Mao et al., 2003). La compatibilidad tisular superior que exhibe el quitosano puede atribuirse en un principio a su similaridad estructural con el glucosaminoglicano en la MEC (Hollinger y Battison, 1986; Cima et al., 1991).

El quitosano es un copolímero lineal de $\beta$ (Lee et al., 2001; Chen et al., 2005; Pachence et al., 1996; Berthod et al., 1994) unido a 2-acetamido-2-deoxi-b-D-glucopiranosa y 2-amino-2-deoxi-b-Dglicopiranosa (Figura 1). Es fácilmente obtenido por deacetilación de quitina, un polisacárido ampliamente distribuido en la naturaleza (e.g. crustáceos, insectos y ciertos hongos) (Chandy y Sharma, 1990 y 1993; Hirano, 1996). El quitosano ha sido reportado como un polímero natural biocompatible, bioabsorbible y particularmente es considerado un excelente acelerador de los procesos de cicatrización celular. Adicionalmente, se encontró que los oligómeros de quitosano 
producidos por la degradación enzimática por parte de enzimas tisulares resultan ser beneficiosos para la regeneración de los tejidos en las secciones cicatrizadas de las heridas.

Además, en contraste con la rápida degradación del colágeno, el quitosano es lentamente biodegradado in vitro, y se ha hallado que las esponjas de colágeno incorporadas con quitosano mejoran la resistencia mecánica (Yang et al., 2004). Estudios previos mostraron que las esponjas quitosano-colágeno fueron favorables para el crecimiento de fibroblastos, sin efectos inflamatorios o reacciones alérgicas presentadas después de la implantación (Pianigiani, 1999; Zamora, 2008).

Este trabajo utiliza quitosano nativo aislado de líneas de desecho de la producción de camarón y colágeno aislado de desechos de la piel de tilapia de cultivo; con estos biopolímeros se sintetizaron materiales compuestos a partir de la mezcla de colágeno y quitosano a diferentes proporciones molares. Los compositos de colágenoquitosano fueron formulados como andamiajes en $3 \mathrm{D}$ similares a una esponja, aplicando tecnologías previamente desarrolladas en nuestro grupo de investigación, basadas en evaporación de solvente mediante liofilización. Los andamiajes de colágeno-quitosano fueron caracterizados de acuerdo con sus propiedades térmicas (análisis termogravimétrico) y morfología (microscopía de barrido electrónico). Finalmente, se estudió el efecto de la adición de un agente porógeno en las propiedades de absorción de agua y la morfología de los andamiajes tridimensionales.

\section{Materiales y Métodos}

\section{Materiales}

Todos los reactivos fueron grado analítico o superior (SigmaAldrich, St. Louis, MO, USA). Quitosano grado farmacéutico (aislado de conchas de camarón), con $95 \%$ de desacetilación, calculado empleando la técnica de ${ }^{1} \mathrm{HRMN}, \mathrm{Pm} 185 \mathrm{kDa}$ (calculado con la técnica de viscosidad específica) y colágeno (aislado de la piel de tilapia, Oreochromis sp), y gentilmente aportados por el Laboratorio de Investigación de Polímeros de la Universidad Nacional (POLIUNA) de Costa Rica.

\section{Preparación del andamio}

Una disolución de quitosano $(2 \%, \mathrm{~m} / \mathrm{v})$ (Sigma, USA) fue lentamente adicionada (por gotas) a una suspensión de colágeno $(5 \%, \mathrm{~m} / \mathrm{v})$ para formar una mezcla compuesta de quitosano-colágeno, en una proporción final de 80:20, v/v. Después de eliminar las burbujas de aire con vacío, la mezcla colágeno-quitosano fue colocada dentro de moldes de vidrio liofilizados hasta obtener una matriz porosa de colágeno y quitosano.

\section{Análisis térmico}

Las propiedades térmicas de los andamiajes 3D elaborados a partir de los bioconjugados quitosano-colágeno se evaluaron mediante termogravimetría (TG) en un analizador termogravimétrico TA-Q50, en atmosfera de nitrógeno y un intervalo de temperaturas de 20 a $600{ }^{\circ} \mathrm{C}$ y una velocidad de calentamiento de $10{ }^{\circ} \mathrm{C} / \mathrm{min}$.

\section{Capacidad de absorción de agua}

La capacidad de absorción de agua del andamio quitosano-colágeno fue determinada sumergiendo el andamio en un buffer salino de fosfato
7.4 (PBS), a temperatura ambiente. Un peso conocido del andamio quitosano-colágeno $(200 \mathrm{mg})$ fue colocado en el medio por un periodo de tiempo requerido. El peso húmedo del andamio fue determinado primero secando la membrana con papel de filtro para remover el agua absorbida de la superficie, luego pesado inmediatamente en una balanza electrónica. El porcentaje de agua absorbido por el andamio de quitosano-colágeno en el medio es entonces calculado empleando la siguiente fórmula:

$$
E_{s w}=\left[\frac{W_{e}-W_{0}}{W_{0}}\right] \times 100
$$

Donde $\mathrm{E}_{\mathrm{sw}}$ es el porcentaje de agua absorbido del andamio al equilibrio, $\mathrm{W}_{\mathrm{e}}$ denota el peso del andamio al equilibrio con el agua absorbida y $\mathrm{W}_{\mathrm{o}}$ es el peso inicial del andamio. Cada experimento fue repetido tres veces y el valor promedio fue tomado como el porcentaje de agua absorbida.

\section{Análisis morfológico de superficie}

La microestructura del andamio quitosano-colágeno $(80: 20, \mathrm{v} / \mathrm{v})$ fue examinada sobre un microscopio de electrón explorador (SEM) a una magnificación de $20 \mathrm{kx}$. El ángulo de inclinación de cada muestra fue de 30 grados.

\section{Introducción de agentes de formación de poro en los andamiajes tridimensionales}

Con el objetivo de incrementar la porosidad de las matrices 3D bioconjugadas y potenciar sus propiedades para el crecimiento y la proliferación de células epiteliales sobre el andamiaje, se evaluó el efecto de introducción de agentes porogénicos en las matrices biopoliméricas compuestas. Para este efecto se mezclaron las disoluciones de bioconjugados preparadas con disoluciones de agentes formadores de poro (sacarosa, cloruro de sodio y glucosa) en concentraciones de 0,1 y $0,5 \% \mathrm{~m} / \mathrm{v}$, respectivamente. Una vez mezclada la mezcla de bioconjugado con el agente porogénico, se prepararon los andamiajes 3D según la metodología descrita anteriormente y se procedió a su caracterización física y química.

\section{Resultados y Discusión}

\section{Caracterización química y física del bioconjugado quitosano-polifenol}

El quitosano se une físicamente al colágeno por medio de interacciones de puente de hidrógeno, debido a la disponibilidad del grupo amino y de los grupos hidroxilo. Esta interacción permite el desarrollo de biomateriales estables, tales como biomembranas de nanopartículas, bioespumas y andamios de tejido.

La Figura 1 presenta con fines ilustrativos una imagen del andamio de quitosano-colágeno tipo-esponja 3D.

El análisis térmico del andamio de quitosano-colágeno 3D por termogravimetría (TG) muestra un comportamiento intermedio para el biocompuesto quitosano-colágeno entre ambos de sus constituyentes en forma pura. La Figura 2 incluye el termograma TG del andamio modelo analizado. 

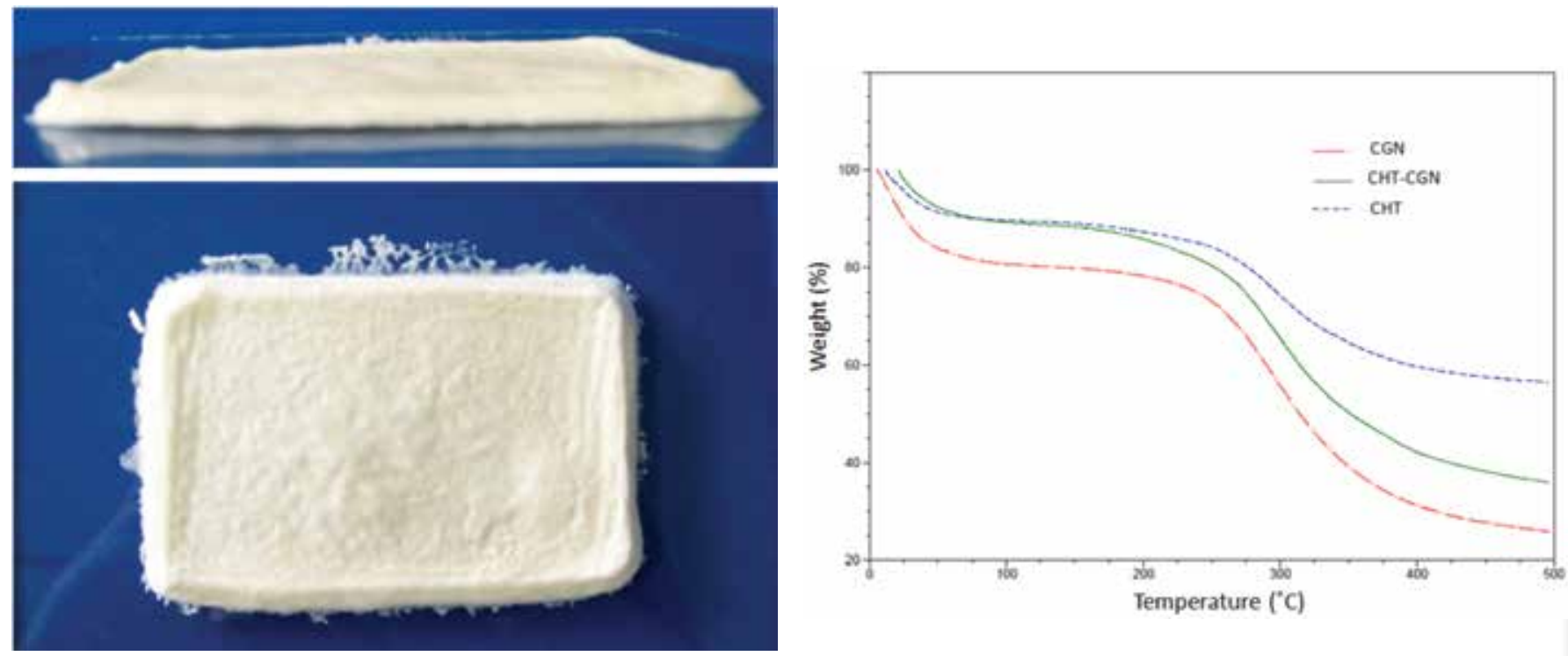

Figura 1. Imagen ilustrativa que representa un andamiaje tridimensional (3D) de quitosano-colágeno $(80: 20, v / v)$ en su sección transversal (arriba) y superficial (abajo).

Figura 2. Termogramas por termogravimetría (TG) de andamiajes 3D de colágeno-quitosano seleccionados. Quitosano (CHT), colágeno (CGN) y andamiaje 3D quitosano-colágeno 80:20, v/v (CHT-CGN).
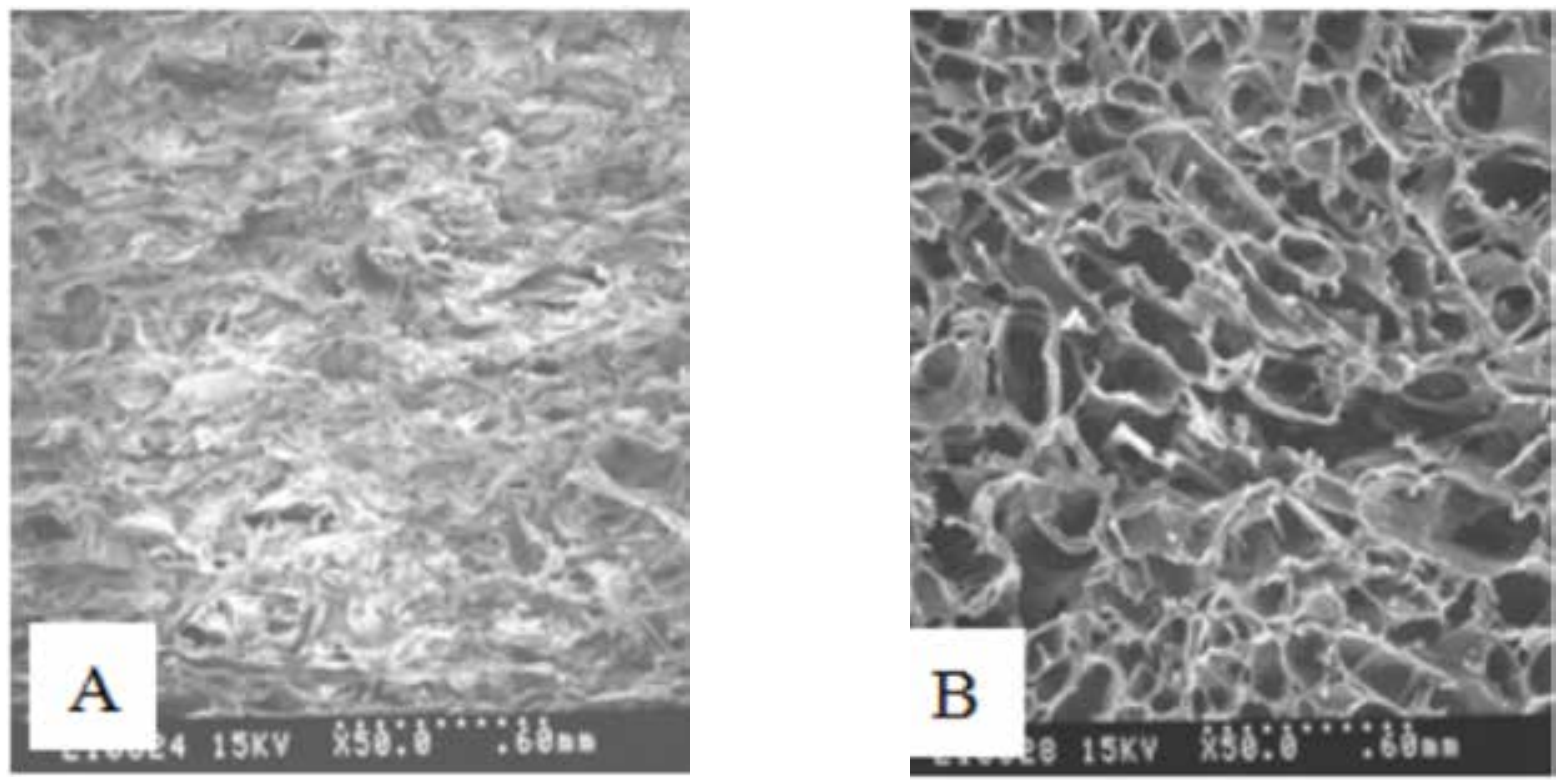

Figura 3. Micrografías SEM para andamiajes obtenidos a partir del bioconjugado quitosano-colágeno $80: 20 \mathrm{v} / \mathrm{v}$, sin proceso de liofilización (A) y posterior al proceso de liofilización (B).

\section{Análisis de morfología superficial}

Las micrografías obtenidas por SEM muestran un cambio en la morfología superficial del sistema bioconjugado antes y después del proceso de liofilización. En la Figura 3 se representan las imágenes superficiales de un sistema bioconjugado sin liofilizar y luego del proceso de liofilización.

En la Figura 3B resulta sencillo percibir el efecto de la técnica de liofilización en la formación de poros en el interior del andamiaje, lo que le confiere las propiedades físicas similares a una esponja. 


\section{Efecto de la adición de un agente porógeno en las propiedades físicas de los andamiajes 3D de colágeno-quitosano}

La prueba de absorción de humedad es una técnica que da una idea de la capacidad de un soporte para absorber humedad, así como de la estabilidad durante su exposición a parámetros controlados. La habilidad que posea para retener cierto porcentaje de agua estará relacionada con la morfología de los apósitos biológicos. La prueba de absorción de humedad para los respectivos andamiajes 3D depende directamente de la naturaleza de los biopolímeros presentes en los andamiajes, así como de la proporción empleada. Si bien es acertado que las proporciones empleadas de los biopolímeros para la elaboración de los andamiajes es la recomendada por Zamora (2008), los mismos se mantienen constantes para todos los biocomposites como parte de un proceso de homologación en los respectivos andamiajes. Esta proporción corresponde a un $80 \%$ de quitosano y a un $20 \%$ de colágeno, en volumen, por lo que las variables presentadas por estos andamiajes se deben básicamente a la morfología, la cual se atribuye al agente porógeno utilizado para dicha matriz. En la Figura 4 se observa el comportamiento de los andamiajes durante el ensayo de absorción de agua.

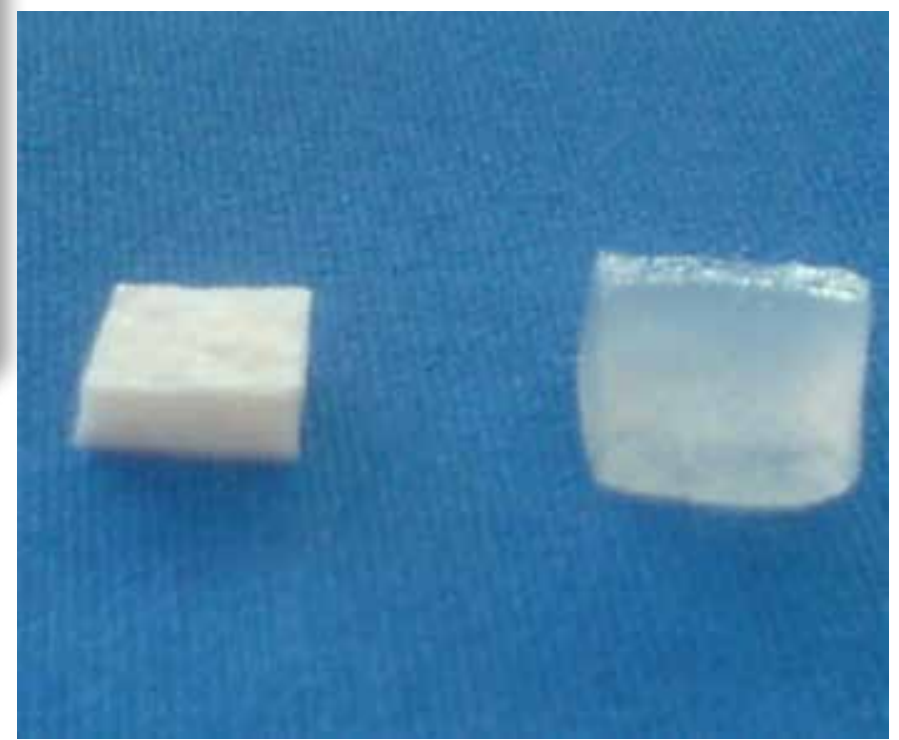

Figura 4. Representación de la capacidad de absorción de agua de los andamiajes 3D de quitosano-colágeno $(80: 20 \mathrm{v} / \mathrm{v})$.

En la Figura 5 se presenta la gran similitud por debajo del $70 \%$ de humedad relativa para todos los diferentes andamiajes $3 \mathrm{D}$; a partir del $85 \%$ de humedad relativa se evidencia una diferencia en los andamiajes elaborados al $0,1 \% \mathrm{~m} / \mathrm{v}$ y $0,5 \% \mathrm{~m} / \mathrm{v}$ con $\mathrm{NaCl}$ y, de igual forma, a humedades relativas del $100 \%$ ambos andamiajes $3 \mathrm{D}$ presentan las máximas absorciones de humedad.

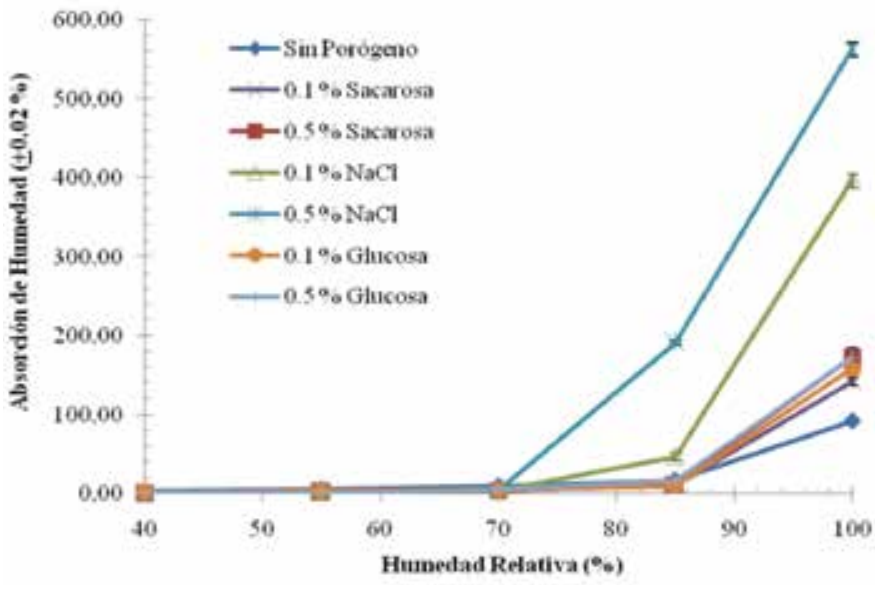

Figura 5. Efecto de la adición de agente porógeno en la capacidad de absorción de agua de los andamiajes quitosano-colágeno $(20: 80, v / v)$

Se puede observar un ascenso para la absorción de humedad en cada uno de los andamiajes que emplean concentraciones del 0,5\% $\mathrm{m} / \mathrm{v}$, según los diversos agentes porógenos. Variables morfológicas como la densidad y tamaño de poro son prácticamente el efecto que produce diferencias en cada uno de los andamiajes 3D.

La absorción de humedad que presenta cada uno de los biocomposites altera significativamente las dimensiones de los soportes 3D, por lo que es importante conocer las condiciones de almacenamiento o preservación de los mismos. Las matrices sometidas a atmósferas controladas con condiciones superiores al $85 \%$ de humedad relativa se alteran física y morfológicamente. El análisis de absorción de humedad no produce cambios importantes en los andamiajes como los presenta el análisis de hinchamiento. Un soporte $3 \mathrm{D}$ al $0,1 \% \mathrm{~m} / \mathrm{v}$ con sacarosa tenía originalmente dimensiones promedio de $0,7 \times 0,7 \times 0,25 \mathrm{~mm}$, y posterior al análisis de absorción de humedad las dimensiones promedio variaron levemente a $0,8 \times 0,7 \times 0,30$ $\mathrm{mm}$, y a 1,1x1,0x0,43 mm después de un análisis de hinchamiento.

La elaboración de andamiajes 3D a partir de diferentes agentes porógenos presenta variedades morfológicas significativas y se atribuyen a efectos positivos en la absorción de humedad a través del soporte; los andamiajes al $0,1 \% \mathrm{~m} / \mathrm{v}$ y $0,5 \% \mathrm{~m} / \mathrm{v}$ con $\mathrm{NaCl}$ son los que presentaron los resultados más importantes como potenciales apósitos biológicos dentro del área de ingeniería de tejidos. Sin embargo, no se descarta la posible evaluación de un crecimiento celular en los demás andamiajes 3D.

El estudio de microscopía electrónica de barrido (SEM) se llevó a cabo en todos los andamiajes 3D para conocer las variables morfológicas que determinan en gran medida el comportamiento de la matriz en los diferentes análisis realizados. Variables como el tamaño del poro, las interconexiones entre poros, la densidad de poros, así como la naturaleza del porógeno y la naturaleza química de los biomateriales empleados para la confección del soporte, son datos de relativa importancia.

Todos los andamiajes 3D tuvieron diferencias significativas en su morfología (Figura 6). Un soporte 3D elaborado a partir de 0,1 $\% \mathrm{~m} / \mathrm{v}$ con $\mathrm{NaCl}$ presentó una pobre densidad del poro, en donde prácticamente no se definen claramente la presencia de poros y las interconexiones entre éstos. También presentaron una forma muy heterogénea, irregular y de apariencia rugosa a nivel superficial. Si bien no se observa una buena porosidad, el tamaño de poro reportado es de $136 \mu \mathrm{m}$, con una desviación estándar de $+34 \mu \mathrm{m}$. Un soporte 3D creado con $\mathrm{NaCl}$ como agente porógeno al $0,5 \% \mathrm{~m} / \mathrm{v}$ presentó una alta densidad de poro, con interconexiones entre poros definidas. Los poros en esta matriz se observan de forma irregular a lo largo de toda la matriz con un tamaño de poro reportado de $272 \mu \mathrm{m}$ y una desviación estándar de $+60 \mu \mathrm{m}$. 
El efecto que provoca una mayor concentración de este agente porógeno $(\mathrm{NaCl})$ en el soporte es significativo. La diferencia respecto a la anisotropía se atribuye a la repulsión que proveen altas concentraciones de $\mathrm{NaCl}$ para sistemas poliméricos, en donde la naturaleza iónica del agente porógeno provee un efecto de repulsión entre las cadenas poliméricas resultado de la porosidad en la matriz. Al emplear bajas concentraciones de $\mathrm{NaCl}$, hay un efecto contrario que podría deberse a las interacciones iónicas entre biopolímero/agente porógeno, por una pobre separación entre las cadenas poliméricas, atribuido a la pobre densidad de poros en la matriz.

Para un soporte 3D en el que se emplea sacarosa como agente porógeno al $0,1 \% \mathrm{~m} / \mathrm{v}$, se observó una alta densidad de poro y una clara interconexión entre poros. Sin embargo, los tamaños de poro son muy heterogéneos y de forma muy irregular a lo largo de toda la matriz, y el tamaño del poro reportado para este soporte es de $215 \mu \mathrm{m}$, con una desviación estándar de $+36 \mu \mathrm{m}$. No obstante, un soporte 3D creado a partir de $0,5 \% \mathrm{~m} / \mathrm{v}$ con sacarosa presentó una alta densidad de poro, con claras interconexiones entre ellos. De igual forma que en el soporte creado con bajas concentraciones del agente porógeno de la misma naturaleza, se observó una irregularidad y heterogeneidad entre poros a lo largo de la matriz, y el tamaño del poro reportado para este soporte es de $226 \mu \mathrm{m}$, con una desviación estándar de $+65 \mu \mathrm{m}$.
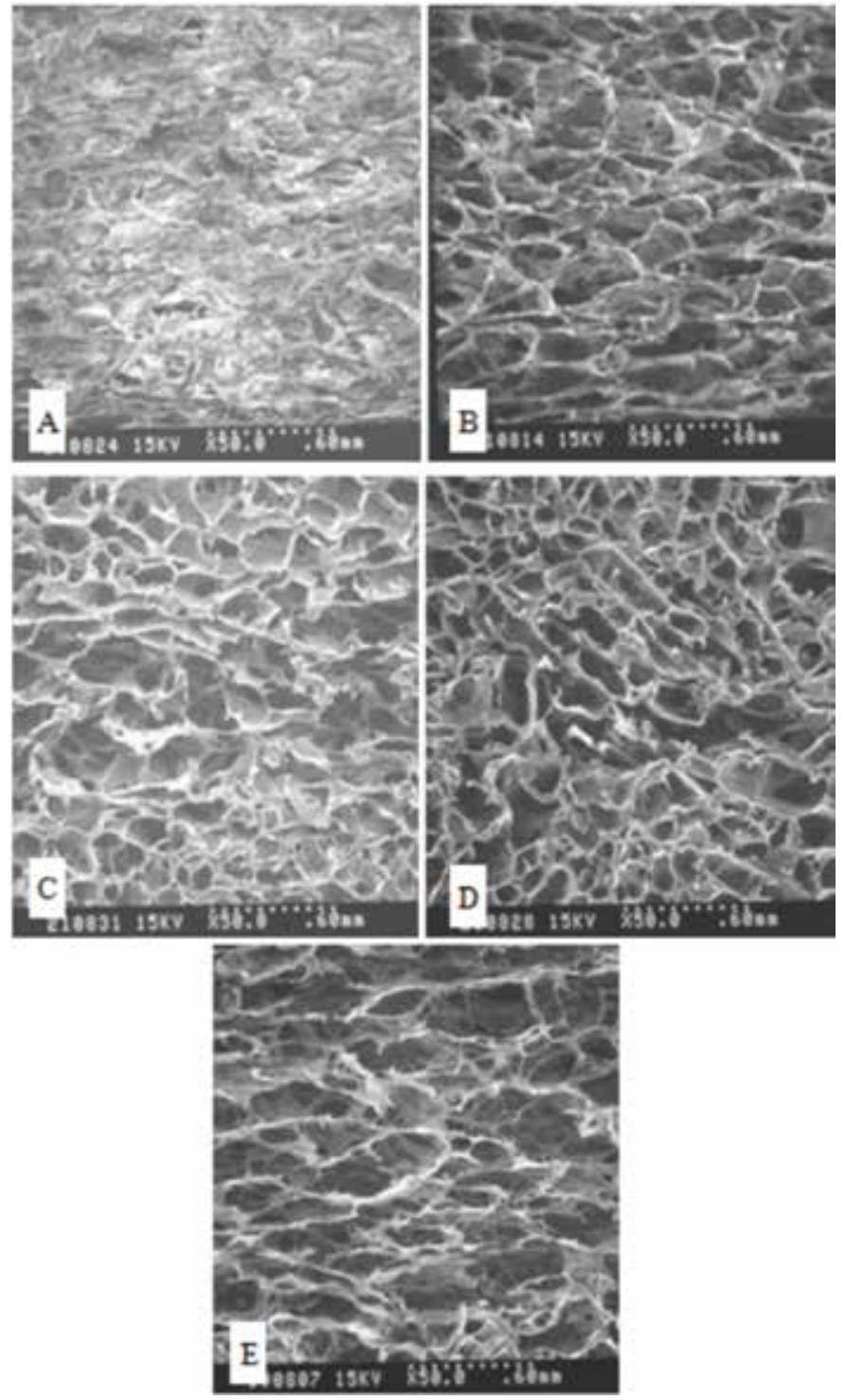

Figura 6. Efecto de la adición de agentes porógenos en la morfología superficial de andamiajes 3D colágeno-quitosano 20:80 visualizados por SEM.
Para un soporte 3D en el que se emplea glucosa como agente porógeno al $0,1 \% \mathrm{~m} / \mathrm{v}$ se observó una alta densidad de poros, así como buena interconexión entre cada poro, la cual se presenta de forma clara y de apariencia rígida; el tamaño de poro reportado para este soporte es de $211 \mu \mathrm{m}$, con una desviación estándar de $+35 \mu \mathrm{m}$. El poro se observa de manera constante y heterogénea en todas sus dimensiones como resultado de una buena anisotropía en la matriz. Por otra parte, un soporte 3D elaborado a partir de $0,5 \% \mathrm{~m} / \mathrm{v}$ con glucosa presentó de igual forma una alta densidad de poro, con diferencias en las interconexiones porosas, ya que algunas son más definidas que otras. El tamaño de poro reportado para este soporte es de $239 \mu \mathrm{m}$, con una desviación estándar de $+51 \mu \mathrm{m}$, y se observa de manera más homogénea y constante a lo largo de todo el soporte. Sin embargo, posee una apariencia irregular, lo cual significa que no es esférico.

Finalmente, un soporte 3D creado sin el uso de un agente porógeno presentó alta densidad de poro, con interconexiones entre poros en forma hilada. Este efecto se atribuye a la naturaleza fibrosa de los biopolímeros empleados en la elaboración de la matriz. Los tamaños de poro son muy heterogéneos y de forma irregular y el tamaño del poro reportado para este soporte es de $264 \mu \mathrm{m}$, con una desviación estándar de $+113 \mu \mathrm{m}$. Con este soporte se concluye que el empleo de un agente porógeno en la matriz produce diferentes efectos morfológicos atribuidos a las interacciones físicas en un sistema polimérico como este, las cuales van a depender directamente de la naturaleza química del porógeno.

Andamiajes 3D elaborados con el uso de glucosa y sacarosa presentaron similitudes en cuanto al tamaño del poro en ambas concentraciones $(0,1$ y $0,5 \% \mathrm{~m} / \mathrm{v})$. No obstante, el comportamiento presentado en los diferentes estudios de hinchamiento, absorción de humedad, análisis térmicos y análisis de determinación del perfil de grosores son aportes clave para descartar el uso de glucosa como agente porógeno en cualquiera de las concentraciones realizadas en este estudio.

Los parámetros que se reportan a partir del estudio de microscopía postulan los andamiajes 3D elaborados a partir de colágeno y quitosano como sustitutos dérmicos promisorios para llevar a cabo crecimientos celulares. El tamaño de poro es un requisito fundamental que potencializa un biocomposite. Cabe destacar que el proceso de obtención propuesto en este trabajo de investigación permitió obtener andamiajes 3D con condiciones y parámetros aptos dentro de lo propuesto en la literatura (Nazarov et al., 2004; Cao et al., 2006), en donde se plantean rangos fundamentales para el tamaño de poro con un mínimo de $100 \mu \mathrm{m}$ y un máximo de $300 \mu \mathrm{m}$, parámetros obtenidos por este proceso de fabricación de andamiajes $3 \mathrm{D}$.

\section{Conclusiones}

Los andamiajes porosos 3D, similares a una esponja, preparados a partir de biocompositos quitosano-colágeno $(80: 20, \mathrm{v} / \mathrm{v})$ para aplicaciones en ingeniería de tejidos han sido optimizados exitosamente en cuanto a sus propiedades térmicas (TG) y morfológicas (SEM), y se estudió el efecto de la adición de diferentes agentes formadores de poro en la capacidad de absorción de agua y morfología superficial de los andamiajes modelo. Actualmente nos encontramos iniciando ensayos de viabilidad para crecimiento de líneas celulares sobre los andamiajes 3D desarrollados utilizando modelos in vitro con células epiteliales. Los resultados obtenidos hasta el momento evidencian que los andamiajes 3D de colágeno-quitosano pueden constituir un sistema modelo apropiado para el crecimiento celular y con un gran potencial para su aplicación en el desarrollo de piel artificial mediante las herramientas de la ingeniería de tejidos. De forma general, las investigaciones presentadas en este trabajo permiten concluir que los desechos de tilapia y de camarón pueden considerarse como fuentes apropiadas para la obtención de derivados de mayor valor agregado con potencial innovador para aplicaciones biomédicas. 


\section{Referencias}

- BERTHOD, F.; SAINTIGNY, G.; CHRETIEN, F.; HAYEK, D.; COLLOMBEL, C.; DAMOUR, O. Optimization of thickness, pore size and mechanical properties of a biomaterial designed for deep burn coverage. En: Clin. Mater. 1994, 15:259-65.

- BERTHOD, F.; HAYEK, D.; DAMOUR, O.; COLLOMBEL, C. Collagen synthesis by human fibroblasts cultured within a collagen sponge. En: Biomaterials. 1993, 14:749-54.

- CAO, Y.; CROLL, T.I.; LEES, J.G.; TUCH, B.E.; COOPER-WHITE, J.J. Scaffolds, stem cells and tissue engineering: A potent combination. En: Chem. Inform. 2006, 37:15-21.

- CHANDY, T.; SHARMA, C.P. Chitosan matrix for oral sustained delivery of ampicillin En: Biomaterials. 1993, 14:939-944.

- CHANDY, T.; SHARMA, C.P. Chitosan: as a biomaterial. En: Biomater. Artif. Cell Artif. Org. 1990, 18:1-24.

- CHEN, G.; SATO, T.; OHGUSHI, H.; USHIDA, T.; TATEISHI, T.; TANAKA, J. Culturing of skin fibroblasts in a thin PLGA-collagen hybrid mesh. En: Biomaterials. 2005, 26:2559-66.

- CIMA, L.G.; VACANTI, J.P.; INGBER, D.; MOONEY, D.; LANGER, $\mathrm{R}$. Tissue engineering by cell transplantation using degradable polymer substitutes. En: J. Biomech. Eng. 1991, 113:143-151.

- HIRANO, S. Chitin biotechnology applications. En: Biotechnol Annu. Rev. 1996, 2:237-258.

- HOLLINGER, J.O.; BATTISON, G.C. Biodegradable bone repair materials: synthetic polymers and ceramics. En: Clin. Orthop. 1986, 207:290-305.

- LAURENCIN, C.T.; EL-AMIN, S.F.; IBIM, S.E.; WILOUGH, D.A.; ATTAWIA, M.; ALLOCK, H.R. AMBROCIO, A.A. A highly porous 3-dimensional polyphosphazene polymer matrix for skeletal tissue regeneration. En: J. Biomed. Mater. Res. 1996, 30:133-138.

- LEE, CH.; SINGLA, A.; LEE, Y. Biomedical applications of collagen. En: Int. J. Pharm. 2001, 221:1-22.

- MA, J.B.; WANG, H.J.; HE, B.L.; CHEN, J.T. A preliminary in vitro study on the fabrication and tissue engineering applications of a novel chitosan bilayer material as a scaffold of human neofetal dermal fibroblasts. En: Biomaterials. 2001, 22:331-6.

- MAO, J.; ZHAO, L.; YAO, K.; SHANG, Q.; YANG, G.; CAO, Y. Study of novel chitosan-gelatin artificial skin in vitro. En: J Biomed Mater Res A. 2003, 64:301-8.

- MUZARELLI, R.A.A. Biochemical significance of exogenous chitins and chitosans in animals and patients. En: Carbohydr. Polym. 1993 20:7-16.

- MUZZARELLI, R.A.A.; ZUCCHINI, C.; ILARI, P.; PUGNALONI, A.; MATTIOLI-BELMONTE, M.; BIAGINI, G. Stimulatory effect on bone formation exerted by a modified chitosan. En: Biomaterials. 1993, 14:925-929.

- NAZAROV, R.; JIN, H.J.; KAPLAN, D.L. Porous 3D scaffolds from regenerated silk fibroin. En: Biomacromolecules. 2004, 5:718-726.

- OJEH, N.O.; FRAME, J.D.; NAVSARIA, H.A. In vitro characterization of an artificial dermal scaffold. En: Tissue Eng. 2001, 7:457-72.

- OKAMOTO, Y.; SHIBAZAKI, K.; MINAMI, S.; MATSUHASHI, A.; TANIOKA, S.; SHIGEMASA, Y. Evaluation of chitin and chitosan on open wound healing in dogs. En: $J$ Vet Med Sci. 1995, 57:851-4.

- PACHENCE, J.M. Collagen-based devices for soft tissue repair. En: $J$ Biomed Mater Res. 1996, 33:35-40.

- PARK, S.N.; LEE, H.J.; LEE, K.H.; SUH, H. Biological characterization of EDC crosslinked collagen-hyaluronic acid matrix in dermal tissue restoration. En: Biomaterials. 2003, 24:1631-41.

- PATEL, V.R.; AMIJI, M.M. Preparation and characterization of freezedried chitosan-poly(ethylene oxide) hydrogels for site-specific antibiotic delivery in the stomach. En: Pharm. Res. 1996, 13:588-593.

- PIANIGIANI, E.; ANDREASSI, A.; TADDEUCCI, P.; ALESSANDRINI, C.; FIMIANI, M. ANDREASSI, L. A new model for studying differentiation and growth of epidermal cultures on hyaluronanbased carrier. En: Biomaterials. 1999, 20:1689-94.

- VASUDEV, S.C.; CHANDY, T.; SHARMA, C.P. Development of chitosan-polyethylene vinyl acetate co-matrix: controlled release of aspirin-heparin for preventing cardiovascular thrombosis. En: Biomaterials. 1997, 18:375-381.

- YANG, Y.; ZHOU, Y.; TAN, W.S. Effect of additives on collagen sponges for bioactive artificial skin. En: J Funct Polym. 2004, 17:396400 .
- YAYLAOGLU, M.B.; KORKUSUZ, P.; ORS, U.; KORKUSUZ, F.; HASIRCI, V. Development of calcium phosphate-gelatin composite as a bone substitute and its use in drug release. En: Biomaterials. 1999, 20:711-719.

- YOU, Y.; PARK, W.H.; KO, B.M.; MIN, B.M. Effects of PVA sponge containing chitooligosaccharide in the early stage of wound healing. En: J Mater Sci Mater Med. 2004, 15:297-301.

- ZAMORA, V. Elaboración de apósitos biológicos a partir de colágeno extraído de pieles de tilapia. Heredia: Universidad Nacional de Costa Rica, 2008. (Tesis de grado). 